viện Việt Đức, kết quả tốt và rất tốt $75 \%$, khá $18 \%$, kém 7\%. Ăm Phới Phu Vông (2012) [9] đánh giá 35 bệnh nhân gãy kín LLC xương cánh tay đã $\mathrm{KHX}$ nẹp vít tại bệnh viện 103 , kết quả tốt và rất tốt $80 \%$, trung bình 14,28\%, xấu 5,72\%.

\section{KẾT LUẬN}

Gãy kín liên lồi cầu xương cánh tay ở người trưởng thành loại $C$ theo phân loại của $A O$ là kiểu gãy xương phạm khớp phức tạp. Phẫu thuật kết hợp xương nẹp vít nhắm nắn chỉnh phục hồi về giải phẫu, cố định ổ gãy vững chắc, tạo điều kiện để tập phục hồi chức năng sớm sau phẫu thuật.

\section{TÀI LIỆ THAM KHẢO}

1. Nguyễn Đức Phúc (2005), Gãy đầu dưới xương cánh tay, Sách Chấn thương chỉnh hình, NXB Y hoc, tr 235.

2. Desault P.J (1881), Treatise on fracture, luxations and other affections of the bones, edited by bichat, Transtated by charles caldwel, Philadelphia Kinbar and conrad.

3. Jupiter J.B., Barnes K.A., Goodman., L.J., et al (1993). Multiplane Fractures of the distal the humerus. J Orthop trauma, (3): 216-220.

4. Nguyển Văn Thái, Trân Thanh Mỹ, Bùi Văn Đức (2000), Điều trị phẫu thuật gãy liên lồi cầu xương cánh tay ở người lớn từ năm 1992-1999. Hội nghị Chấn thương chỉnh hình Tp. Hồ Chí Minh.

5. Nguyên Khắc Sinh (2007), Đánh giá kết quả điều trị phâu thuật gãy liên lồi cầu xương cánh tay tại bệnh viện Việt-Đức, Luận văn tốt nghiệp Bác sỹ chuyền khoa 2, Trường Đại hoc Y Hà Nôi.

6. Muller M.E, Nazatian S., Koch P. (1987), AO classification of fractured, Berlin Springer.

7. Huang T.L., Chiu F.Y., Chang T.Y., Chen TH. (2005), The reaults of open reduction and internal fixation in elderly patients with sever Fractures of the distal Humerus; a critical analysis of the resul, Jtrauma. Ja; 58(1): 62-9

8. Đào Đức Hoàng (2005), Đánh giá kết quả điều trị gãy kín phạm khớp đâu dưới xương cánh tay ở người lớn bằng phương pháp kết xương nep vít tai bệnh viện Saint-Paul Hà Nội, Luận văn Thạc sỹ Y học, Hoc viên Quân Y.

9. Âm Phới Phu Vông (2012), Đánh giá kết quả điều trị gãy kín liên lối câu xương cánh tay ở người lớn bằng phương pháp kết xương bên trong tại bệnh viện 103, Luận văn Thạc Sỹ Y học, Học viện Quân Ŷ.

\title{
ĐÁNH GIÁ MỐI LIÊN QUAN GIŨ̃A NỒNG ĐÔ̂ AMH HUYẾT THANH VÀ KẾT QUẢ THỤ TINH TRONG ỔNG NGHIỆM
}

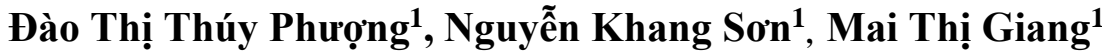

\section{TÓM TẮT}

Mục tiêu: Đánh giá mối liên quan giữa giá trị nồng độ $\mathrm{AMH}$ huyết thanh với kết quả thụ tinh trong ống nghiệm. Phương pháp nghiên cứu: Nghiên cứu mô tả hồi cứu với đối tượng nghiên cứu là 157 phụ nữ trong độ tuổi từ 23-47, điều trị vô sinh bằng phương pháp thụ tinh ống nghiệm tại Trung tâm Hố trợ sinh sản và Công nghệ mô ghép bệnh viện Đại học Y Hà Nội, từ tháng 1/2020 đến tháng 6/2021. Đối tượng được chia thành 3 nhóm theo giá trị $\mathrm{AMH}$ : thấp $<1,25$ $\mathrm{ng} / \mathrm{ml}$, trung bình $1,25-3,57 \mathrm{ng} / \mathrm{ml}$, cao $>3,57 \mathrm{ng} / \mathrm{ml}$ (theo một nghiên cứu về mức đáp ứng buồng trứng tai Viêt Nam trước đó) [1]. Đánh giá các kết quả bao gồm số noãn thu được, số noãn trưởng thành, tỉ lệ thụ tinh, số phôi và chất lượng phôi giai đoạn phân cắt, tỉ lệ thai lâm sàng tương ứng ở 3 nhóm này. Kết quả: Tỉ lệ noãn trưởng thành tî lê thu tinh, tỉ lê phôi khả dụng giai đoạn phân cắt không khác biệt giữa các nhóm AMH. Tuy nhiên, số lượng noãn, số lượng phôi khả dụng giai đoạn phân cắt ở nhóm $\mathrm{AMH}$ thấp thì thấp hơn nhóm ẢMH trung bình, nhóm $\mathrm{AMH}$ trung

${ }^{1}$ Trường Đại học Y Hà Nội

Chịu trách nhiệm chính: Mai Thị Giang

Email: maigiang1995@gmail.com

Ngày nhận bài: 2.8.2021

Ngày phản biên khoa họ: 28.9.2021

Ngày duyệt bài: 4.10.2021 bình thấp hơn nhóm AMH cao có ý nghĩa thống kê. Tỉ lệ thai lâm sàng có sư khác biêt giữa các nhóm $\mathrm{AMH}$. AMH không có giá trị dự đoán chất lượng noãn bào nhưng có khả năng dư đoán được số noãn thu được, số phôi khả dụng và tỉ lệ thai lâm sàng.

Tư khóa: AMH, noã்n trưởng thành, tỉ lệ thụ tinh, phôi giai đoạn phân cắt, thai lâm sàng.

\section{SUMMARY}

\section{THE RELATIONSHIP BETWEEN SERUM AMH} HORMONE CONCENTRATIONSAND IVF OUTCOMES

Objective: To investigate the relationship between serum AMH levels and outcomes of in vitro fertilization. Methods: Descriptive retrospective study. Subjects: 157 infertile women between the ages of 23 and 47 undergoing IVF treatment at Center of IVF and Tissue engineering, Hanoi Medical University Hospital, from January 2020 to June 2021, were divided into 3 groups: low, medium and high AMH concentration ( $<1.25 \mathrm{ng} / \mathrm{mL} ; 1.25-3.57 \mathrm{ng} / \mathrm{mL}$; $>3.57 \mathrm{ng} / \mathrm{mL}$, respectively) based on result of the previous study in Vietnam [1]. The parameters of IVF outcomes including the number of retrieved oocytes, the number of retrieved mature oocytes, the fertilization rate, the number of embryos and the quality of the embryos at the cleavage stage, and the corresponding clinical pregnancy rates were compared among these 3 groups. Results: The groups showed no statistical differences in mature oocyte rates, 
fertilization rates and good quality embryo rates. The number of retrieved oocytes, retrieved mature oocytes, embryos and potential embryos at the cleavage stage in the low AMH level group are smaller than in the medium level group, which is in turn smaller than in the high level group, all the differences are statistically significant. The clinical pregnancy rate showed significant fifferences among the AMH groups. AMH has no predictive value for oocyte quality, but is capable of predicting the number of received oocyte, potential embryos and clinical pregnancy rate.

Keywords: AMH, mature oocyte, fertilization rate, embryo cleavage, clinical pregnancy.

\section{I. ĐĂT VẤN ĐỀ}

Để có thể dự đoán và tiên lượng toàn diên về khả năng thành công cũng như tư vấn kết quả của thụ tinh trong ống nghiệm cần khảo sát rất nhiều yếu tố về cả người vợ và người chồng. Về phía người vợ, xét nghiệm đánh giá dự trữ buồng trứng có ý nghĩa vô cùng quan trọng, giúp tư vấn cho bệnh nhân lựa chọn được chiến lược điêu trị phù hợp, dự đoán được khả năng kém đáp ứng hay đáp ứng quá mức với kích thích buồng trứng. Ngày nay cùng với sự phát triển xã hội, các cặp vợ chồng thường có xu hướng trì hoãn việc sinh con, do đó xét nghiệm đánh giá mức dự trữ buồng trứng là việc làm cần thiết để các cặp vợ chồng có thể lên kế hoạch cho tương lai. Nhiêu phương pháp khảo sát dự trữ buồng trứng được sử dụng như: các xét nghiệm nội tiết tố, siêu âm đếm số lượng nang thứ cấp hai buồng trứng ở đầu chu kì kinh (AFC- Antral Follicle Count).... [2]. Trong đó xét nghiệm nồng độ hormone AMH (Antimullerian Hormon hormon kháng ống cận trung thận) huyết thanh là một hướng đi mới, cho kết quả nhanh chóng, tiện dụng và có độ tin cậy cao đánh giá đáp ứng buồng trứng [3]. Tuy nhiên liệu có mối tương quan nào giữa chỉ số xét nghiệm nồng độ $\mathrm{AMH}$ huyết thanh với kết quả của thụ tinh trong ống nghiệm không? Vì vậy chúng tôi tiến hành nghiển cứu với mục tiêu: Đánh giá mối liên quan giữa nồng độ $A M H$ huyêt thanh với kêt quả thụ tinh trong ống nghiệm.

\section{II. ĐỐI TƯƠNG VÀ PHƯƠNG PHÁP NGHIÊN CỨU}

2.1. Đối tượng nghiên cứu. Toàn bộ các bệnh nhân nữ điều trị vô sinh tại trung tâm Hỗ trợ sinh sản và công nghệ mô ghép (HTSS\&CNMG), Bểnh viện Đại học Y Hà Nội từ tháng 1/2020 đến 6/2021 đã được chuyển phôi ở giai đoạn phân cắt được chia thành 3 nhóm dựa trên nồng độ AMH huyết thanh: thấp, trung bình, cao.

Các trường hợp vô sinh do bất thường về làm tổ và vô sinh do yếu tố cấu trúc giải phẫu (dị dạng tử cung, sau phẫu thuật tử cung...) và yếu tổ tinh trùng bất thường nặng ở người chông (tinh trùng trích xuất, tinh trùng bất động hoặc hình thái bất thường nặng) bị loại ra khỏi nghiên cứu.

\subsection{Phương pháp nghiên cứu}

*Thiết kế nghiên cứu: Nghiên cứu được tiến hành theo phương pháp mô tả hồi cứu. Các bênh nhân được chia thành 3 nhóm theo giá trị nổng độ $\mathrm{AMH}$ huyết thanh lần lượt, nhóm $\mathrm{AMH}$ thấp: $<1,25 \mathrm{ng} / \mathrm{mL}$, trung bình: $1,25 \mathrm{ng} / \mathrm{mL}-$ 3,57 ng/mL, cao: $>3,57 \mathrm{ng} / \mathrm{mL}$, dựa theo một nghiên cứu của Vương Thị Ngọc Lan và cộng sự (2016) về ngưỡng đáp ứng buồng trứng [1].

*Chỉ tiêu nghiên cứu:

- Tuổi vợ, số năm vô sinh.

- AFC, nồng độ AMH huyết thanh.

- Số lượng noã̉n sau chọc hút, số lượng noãn trưởng thành (MII) thu được.

- Số lượng phôi, số phổi tốt, trung bình, xấu theo tiêu chuẩn ALPHA 2010 giai đoạn phân cắt [4], số lượng phôi khả dụng (tổng số phôi tốt và trung bình).

- Tỉ lệ thai lâm sàng: tính bằng số chu kì chuyển phôi có kết quả siêu âm thấy hình ảnh túi noãn hoàng sau chuyển phôi 6 tuần chia trên tổng 100 chu kỳ bắt đầu chuyển phôi của các bệnh nhân (cũng là số chu kỳ chọc hút noãn) [5].

*Xử lí số liệu: Số liệu được thu thập và xử lý bằng phần mềm SPSS 20.0, dùng phép toán thống kê mô tả cho các biến định tính và định lượng, so sánh các giá trị trung bình bằng oneway ANOVA Test, so sánh tỉ lệ bằng Chi-squared Test và Fisher's Exact Test.

*Đạo đức trong nghiên cứu: Nghiên cứu thuộc loaai mô tả hồi cứu, không can thiệp trên bệnh nhân và được sự cho phép của lãnh đạo Trung tâm HTSS\&CNMG, Bệnh viện Đại học Y Hà Nội. Thông tin bệnh nhân được mã hoá, giữ bí mật và chỉ phục vụ cho mục đích nghiên cứu.

\section{KẾT QUẢ NGHIÊN CỨU}

\section{1 Đặc điểm chung của bệnh nhân}

Bảng 1: Đặc điểm chung của bệnh nhân trong nghiên cứu

\begin{tabular}{|c|c|c|c|c|c|}
\hline & $\begin{array}{c}\text { Nhóm AMH } \\
\text { thấp }(n=27) \\
(\widetilde{x} \pm \text { SD })\end{array}$ & $\begin{array}{c}\text { Nhóm AMH trung } \\
\text { bình }(n=70) \\
(\bar{x} \pm \text { SD })\end{array}$ & $\begin{array}{c}\text { Nhóm AMH } \\
\text { cao }(n=60) \\
(\bar{x} \pm \text { SD })\end{array}$ & \begin{tabular}{|c} 
Cả 3 nhóm AMH \\
$(\mathrm{n}=157)$ \\
$(\bar{x} \pm$ SD $)$
\end{tabular} & \\
\hline & $36,0 \pm 5,17$ & $31,01 \pm 1,16$ & $29,32 \pm 3,02$ & $31,19 \pm 4,60$ & \\
\hline
\end{tabular}


VIETNAM MEDICAL JOURNAL N²2 - OCTOBER - 2021

\begin{tabular}{|c|c|c|c|c|c|}
\hline $\begin{array}{c}\text { Thời gian vô } \\
\text { sinh (năm) }\end{array}$ & $5,23 \pm 3,87$ & $3,57 \pm 2,65$ & $2,85 \pm 1,95$ & $12,64 \pm 6,07$ & 0,009 \\
\hline AFC & $7,25 \pm 2,71$ & $11,24 \pm 3,06$ & $17,37 \pm 7,04$ & $3,57 \pm 2,77$ & 0,000 \\
\hline AMH $(\mathrm{ng} / \mathrm{mL})$ & $0,83 \pm 0,29$ & $2,33 \pm 0,63$ & $6,04 \pm 2,89$ & $3,63 \pm 2,90$ & 0,000 \\
\hline
\end{tabular}

*p được tính theo so sánh phương sai ANOVA một yếu tố

Nhận xét: Trong giai đoạn từ tháng 1/2020 đến tháng 6/2021 tại Trung tâm Hỗ trợ sinh sản và Công nghệ Mô ghép có 157 phụ nữ đáp ứng đủ tiêu chuẩn được đưa vào nghiên cứu, trong đó có 27 $(17,19 \%)$ trường hợp xếp vào nhóm AMH thấp, $70(44,6 \%)$ trường hợp xếp nhóm AMH trung bình, $60(38,21 \%)$ trường hợp xếp vào nhóm AMH cao. Các giá trị tuổi, thời gian vô sinh, AFC khác biệt giữa các nhóm AMH với các giá trị p đều nhỏ hơn 0,05.

3.2 Kết quả số lượng, chất lượng noãn phối thu được

Bảng 2. Đặc điểm noãn, phôi của bệnh nhân các nhóm nghiên cứu

\begin{tabular}{|c|c|c|c|c|}
\hline Đặc điểm & $\begin{array}{c}\text { Nhóm AMH thấp } \\
(\mathrm{n}=27)\end{array}$ & $\begin{array}{l}\text { Nhóm AMH trung } \\
\text { bình }(n=70)\end{array}$ & $\begin{array}{c}\text { Nhóm AMH cao } \\
(\mathrm{n}=60)\end{array}$ & $\mathbf{P}^{*}$ \\
\hline Tổng số noãn $\left({ }^{\mathcal{X}} \pm \mathrm{SD}\right)$ & $6,78 \pm 3,17$ & $12,09 \pm 5,49$ & $7,41 \pm 0,95$ & 0,000 \\
\hline $\begin{array}{l}\text { Số noãn trưởng thành (MII) } \\
(\overline{\bar{X}} \pm S D)\end{array}$ & $5,11 \pm 2,66$ & $8,86 \pm 5,06$ & $14,08 \pm 5,99$ & 0,000 \\
\hline Số noãn thụ tinh $(\overline{\bar{x}} \pm S D)$ & $4,67 \pm 2,66$ & $8,10 \pm 4,58$ & $13,03 \pm 5,44$ & 0,000 \\
\hline $\begin{array}{l}\text { Số phôi giai đoạn phân cắt } \\
\qquad(\bar{x} \pm S D)\end{array}$ & $4,37 \pm 2,53$ & $7,76 \pm 4,67$ & $12,55 \pm 5,53$ & 0,000 \\
\hline $\begin{array}{c}\text { Tỉ lệ noãn trưởng thành } \\
\text { (MII) }(\%)\end{array}$ & 76,87 & 73,05 & 73,59 & 0,569 \\
\hline Tỉ lệ noãn MII thụ tinh (\%) & 96,23 & 92,96 & 98,82 & 0,607 \\
\hline Tỉ lệ phôi khả dụng (\%) & 79,75 & 74,20 & 76,45 & 0,547 \\
\hline
\end{tabular}

*p được tính theo so sánh phương sai ANOVA một yếu tố

Nhận xét: Số noãn thu được và số noãn trưởng thành, số phôi giai đoạn phân cắt và số phôi khả dụng thu được của nhóm $\mathrm{AMH}$ cao lớn hơn nhóm $\mathrm{AMH}$ trung bình và nhóm $\mathrm{AMH}$ trung bình thì cao hớn nhóm $A M H$ thấp với các giá trị $p<0,001$. Tuy nhiên tỉ lệ noãn trưởng thành, tỉ lệ noãn MII thụ tinh, tỉ lệ phôi khả dụng của 3 nhóm khác biệt không có ý nghĩ̉a thống kê.

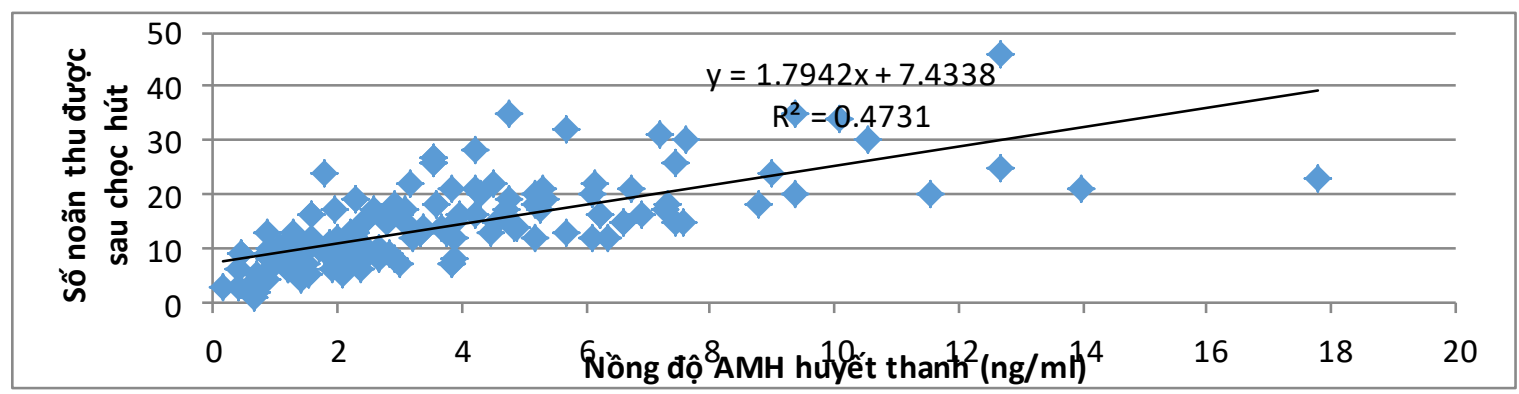

Biểu đồ 1. Tương quan giữa giá trị AMH với số noãn thu được

Nhận xét: Có mối tương quan vừa giữa nồng độ $A M H$ huyết thanh và số lượng noãn thu được với hệ số tương quan là $R=0,688$ với $p=0,000<0,001$

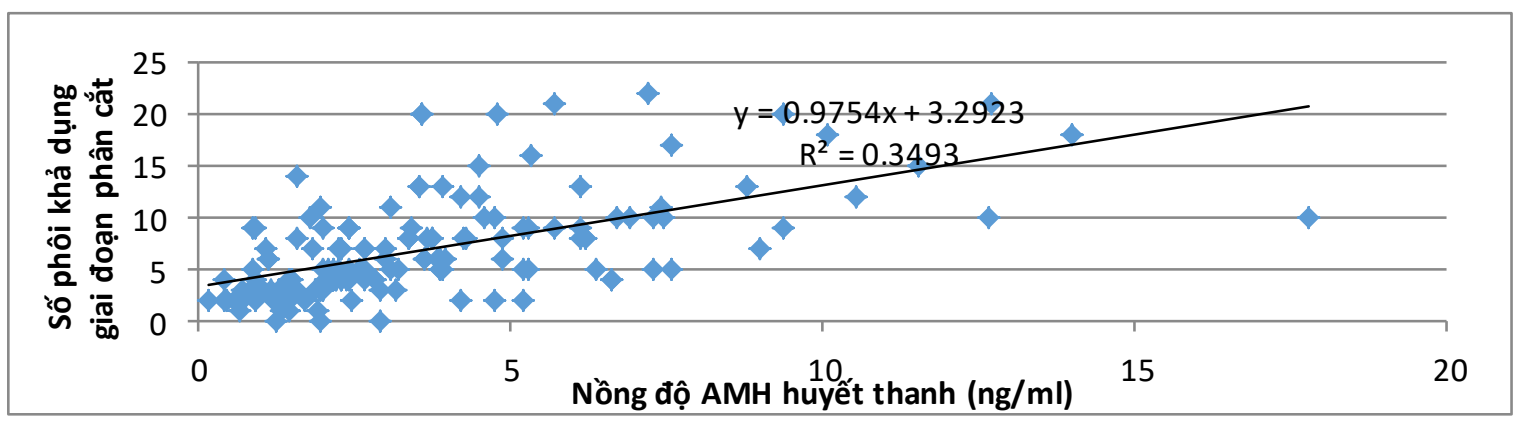

Biểu đồ 2. Tương quan giữa giá trị AMH với số phôi khả dụng thu được. 
Nhận xét: Có mối tương quan vừa giữa nồng độ $A M H$ huyết thanh và số phôi khả dụng giai đoạn phân cắt thu được với hê̂ số tương quan là $R=0,591$ với $p=0,000<0,001$.

3.3. Kết quả tỉ lệ thai lâm sàng

Bảng 3. Tỉ lệ thai lâm sàng của các nhóm nghiên cứu

\begin{tabular}{|c|c|c|c|}
\hline Đặc điểm & $\begin{array}{c}\text { Nhóm AMH thấp } \\
(\mathbf{1})(\mathrm{n}=27)\end{array}$ & $\begin{array}{c}\text { Nhóm AMH trung } \\
\text { bình (2) }(\mathrm{n}=70)\end{array}$ & $\begin{array}{c}\text { Nhóm AMH cao (3) } \\
(\mathrm{n}=60)\end{array}$ \\
\hline Tỉ lệ thai lâm sàng (\%) & 33,3 & 40,6 & 63,3 \\
\hline $\mathbf{P}^{*}$ & $\mathrm{P}_{1,2}=0,512$ & $\mathrm{P}_{2,3}=0,009$ & $\mathrm{P}_{1,3}=0,01$ \\
\hline
\end{tabular}

*p được tính theo so sánh tỉ lệ Chi-squared Test

Nhận xét: Tỉ lệ thai lâm sàng tính trên một tổng số chu kì chuyển phôi đầu tiên của nhóm AMH trung bình có xu hướng cao hơn nhóm $\mathrm{AMH}$ thấp tuy nhiên sự khác biệt này không có ý nghĩa thống kê với $p=0,512$. Tỷ lệ thai lâm sàng của nhóm $A M H$ cao lớn hơn nhóm AMH trung bình và nhóm $A M H$ thấp với các giá trị p đều nhỏ hơn 0,05.

\section{BÀN LUÂ̂N}

Chúng tôi thu thập các kết quả thụ tinh trong ống nghiệm của 157 phụ nữ với 157 chu kì chọc hút noãn (chuyển phôi lần đầu) điều trị thụ tinh trong ống nghiệm tại Trung Tâm hỗ trợ sinh sản và Công nghệ mô ghép Bệnh Viện Đại học Y Hà Nội, các đối tượng trong nghiên cứu này được chia theo 3 nhóm AMH dựa theo một nghiên cứu trước đó của Vương Thị Ngọc Lan và cộng sự (2016) [1]. Với những bệnh nhân chuyển phồi đông, phôi được theo dõi đến ngày 2 , sau đó sẽ đước đông phồi toàn bộ, phôi rã đông sẽ được nuôi lên ngày 3 để chuyển. Ở các bệnh nhẩn chuyển phôi tươi, phôi được chuyển ở giai đoạn ngày 3. Phần lớn các đối tượng nghiên cứu của chúng tôi tiến hành đông phồi toàn bộ và chuyển phôi đông lạnh 1 lần.

*Bàn luận về các đặc điểm và giá trị AMH của các nhóm nghiên cứu: Chúng tôi nhận thấy xu hướng khi giá trị $\mathrm{AMH}$ càng lớn thì độ tuổi trung bình và thời gian vô sinh của nhóm nghiên cứu càng nhỏ và ngược lại số nang noãn cơ sở càng cao. Điều này cũng phù hợp với nhận định $\mathrm{AMH}$ giảm dần theo độ tuổi như theo mô hình của tác giả Kelsey và cộng sự (2011) [6].

Độ tuổi trung bình của bệnh nhân trong nghiên cứu là 31,19: thời gian vổ sinh trung bình 3,57 năm, $A F C$ trung bình là 12,64 và giá trị $A M H$ trung bình là $3,63 \mathrm{ng} / \mathrm{ml}$. Có thể thây độ tuổi của đối tượng trong nghiên cứu của chúng tôi trẻ hơn, AFC trung bình lớn hơn và giá trị $A M H$ trung bình cao hơn so với nghiên cứu của Vương Thị Ngọc Lan (2016) với độ tuổi trung bình đối tượng nghiên cứu là 34, thời gian vô sinh trung bình 5,3 năm, AFC trung bình là 10,52 , AMH trung bình là $3,09 \pm 2,52 \mathrm{ng} / \mathrm{ml}$ [1]. Sự khác biệt về tuổi của này của chúng tôi so với tác giả Vương Thị Ngọc Lan (2016) có thể phần nào phản ánh xu hướng điều trị IVF sớm hơn trước kia.

*Bàn luận về kết quả thụ tinh trong ống nghiệm của các nhóm nghiên cứu. Trong nghiên cứu này, chúng tôi tìm thấy có sự khác biệt về các kêt quả: số noãn thu được sau chọc hút, số noãn trưởng thành, số phổi giai đoạn phân cắt, số phôi khả dụng giai đoạn phân cắt giữa các nhóm nồng độ $A M H$ với ý nghĩa thống kê. Kết luận này tương tự như trong các nghiên cứu của Bingqian Zhang (2019) [7] và Vương Thị Ngọc Lan (2016) [1]. Chúng tôi cũng ghi nhận có tướng quan giữa nồng độ $\mathrm{AMH}$ huyết thanh với số noãn chọc hút, số phôi khả dụng thu được với hệ số tương quan $R=0,688$ và $R=0,591$ tương tự như nghiên cứu của Bingqian Zhang (2019) [7].

Các kết quả khác bao gồm tỉ lệ thụ tinh, tỉ lệ noãn trưởng thành, tỉ lệ phôi khả dụng không khác biệt giữa các nhóm nồng độ $\mathrm{AMH}$, ủng hộ cho nghiên cứu Dai $X$ và cộng sự (2020) khi cho rằng $\mathrm{AMH}$ không có vai trò trong dự đoán chất lượng noãn bào thu được [8]. Điều này không đồng thuận với một số tác giả như Eldar-Geva và cộng sự (2005) [9] coi mức AMH như giá trị định tính về chất lượng tế bào trứng, tỉ lệ thụ tinh.

*Bàn luận về kết quả thai lâm sang. Tỉ lệ thai lâm sàng trên tổng số chu kì chuyển phôi của nhóm $\mathrm{AMH}$ thấp trong nghiên cứu này là 33,3\% (9/27) không khác biệt với nhóm AMH trung bình là $40,6 \%(28 / 70)$ và đều thấp hơn nhóm AMH cao là $63,3 \%(38 / 60)$. Ở nghiên cứu Bingqian Zhang (2019) có cõ mấu 7283 phụ nữ dưới 35 tuổi [6], tỉ lệ thai lâm sàng của 3 nhóm AMH thấp $(0,01-1,32 \mathrm{ng} / \mathrm{ml})$, AMH trung bình $(1,32-3,99 \mathrm{ng} / \mathrm{ml})$ và $\mathrm{AMH}$ cao $(3,99-22,05$ $\mathrm{ng} / \mathrm{ml}$ ) lần lượt là $58,01 \% ; 62,90 \% ; 66,33 \%$; $\mathrm{p}<0,01$ cho tất cả các so sánh cặp. Sự khác biệt về tî lệ thai lâm sàng ở nhóm $\mathrm{AMH}$ thấp và trung bình của chúng tôi so với nghiên cứu này có thể do đối tượng nghiên cứu của chúng tôi bao gồm cả những bệnh nhân trên 35 tuổi và có thể do cõ mẫu nghiên cứu của chúng tôi nhỏ, ngưỡng nồng độ $\mathrm{AMH}$ dùng để phân nhóm trong nghiên cứu của chúng tôi cũng thấp hơn với nghiên cứu 
của Bingqian Zhang (2019) [7]. Do đó chưa thấy được khác biệt về tỉ lệ có thai giữa các nhóm giá trị AMH thấp và trung bình. Chúng tôi hy vọng tiến hành nghiên cứu với cõ̃ mẫu lớn hơn để tìm hiểu sâu hơn về vấn đề này.

\section{KẾT LUÂ̂N}

- Tỉ lệ noãn trưởng thành, tỉ lệ thụ tinh, tỉ lê phôi khả dụng ở giai đoạn phân cắt không có khác biệt giữa các nhóm AMH. Tuy nhiên số lượng noãn, số lượng phôi và số lượng phôi khả dụng khác biệt giữa các nhóm là có ý nghĩa: thấp nhất ở nhóm AMH thấp và cao nhất ở nhóm $\mathrm{AMH}$ cao.

- Nhóm AMH cao có tỷ lệ thai lâm sàng cao hơn có ý nghĩa so với hai nhóm còn lại. Tỉ lệ thai lâm sàng của nhóm $\mathrm{AMH}$ trung bình cao hơn nhóm AMH thấp nhưng không có ý nghĩa thống kê.

- AMH không có giá trị dự đoán chất lượng noãn bào nhưng có khả năng dự đoán được số noãn thu được, số phôi khả dụng và tỉ lệ thai lâm sàng.

\section{Lờ' CẢM ƠN}

Chúng tôi trân trọng gửi lời cảm ơn đến ban lãnh đao, quý thây cô, đồng nghiệp tại Trung tâm Hổ trợ sinh sản và Công nghệ mô ghép, Bênh viện Đại học Y Hà Nội đã tạo điều kiện và giúp đỡ để chúng tôi hoàn thành nghiên cứu này. Các tác giả cam kết không có tranh chấp về quyền lợi.

\section{TÀI LIÊU THAM KHẢO}

1. Vương Thị Ngọc Lan (2016). Giá trị xét nghiệm AMH,FSH và AFC dự đoán đáp ứng buồng trứng trong thụ tinh ống nghiệm. Luận văn Tiến sỹ y học, Đại học Y Dược Hồ Chí Minh, 186.

2. Broekmans F.J., Kwee J., Hendriks D.J., et al. (2006). A systematic review of tests predicting ovarian reserve and IVF outcome. Hum Reprod Update, 12(6), 685-718.

3. Xu H., Zeng L., Yang R., et al. (2017). Retrospective cohort study: $\mathrm{AMH}$ is the best ovarian reserve markers in predicting ovarian response but has unfavorable value in predicting clinical pregnancy in $\mathrm{GnRH}$ antagonist protocol. Arch Gynecol Obstet, 295(3), 763-770.

4. ALPHA Scientists In Reproductive Medicine and ESHRE Special Interest Group Embryology (2011). Istanbul consensus workshop on embryo assessment: proceedings of an expert meeting. Reprod Biomed Online, 22(6), 632-646.

5. Zegers-Hochschild F., Adamson G.D., de Mouzon J., et al. (2009). The International Committee for Monitoring Assisted Reproductive Technology (ICMART) and the World Health Organization (WHO) Revised Glossary on ART Terminology, 2009. Human Reproduction, 24(11), 2683-2687.

6. Kelsey T.W., Wright P., Nelson S.M., et al. (2011). A validated model of serum anti-müllerian hormone from conception to menopause. PLOS ONE, 6(7), e22024.

7. Zhang B., Meng Y., Jiang $X$., et al. (2019). IVF outcomes of women with discrepancies between age and serum anti-Müllerian hormone levels. Reprod Biol Endocrinol, 17(1), 58.

8. Dai X., Wang Y., Yang H., et al. (2020). AMH has no role in predicting oocyte quality in women with advanced age undergoing IVF/ICSI cycles. Sci Rep, 10(1), 19750.

9. Eldar-Geva T., Ben-Chetrit A., Spitz I.M., et al. (2005). Dynamic assays of inhibin $B$, antiMullerian hormone and estradiol following $\mathrm{FSH}$ stimulation and ovarian ultrasonography as predictors of IVF outcome. Human Reproduction, 20(11), 3178-3183.

\section{KIẾN THỨC VÀ THỰC HÀNH VỀ PHÒNG CHỐNG BÊNH RĂNG MIỆNG CỦA HỌC SINH HAI TRƯỜNG TIỂU HỌC THÀNH PHỐ ĐIỆN BIÊN PHỦ, TỈNH ĐIỆN BIÊN NĂM 2018}

\section{TÓM TẮT}

Một nghiên cứu cắt ngang tiến hành trên 381 hoc sinh 2 trường tiểu học trên địa bàn thành phố Điệ̉n Biên Phủ, tỉnh Điên Biên từ tháng 7/2018 đến tháng 2/2019. Mục tiêu của nghiên cứu nhằm xác định kiến thức, thực hành về phòng chống bệnh răng miệng của

*Trường Đại hơ Y Dược Thái Binh

Chịu trách nhiệm chính: Ngô Văn Mạnh

Email: manhsdh@gmail.com

Ngày nhận bài: 28.7.2021

Ngày phản biên khoa hoc: 27.9.2021

Ngày duyệt bài: 4.10 .2021
Ngô Văn Mạnh*, Lê Đức Cường*

học sinh tiểu học. Kết quả nghiên cứu cho thấy: Có $36,9 \%$ hoc sinh biết cách là chải răng xoay tròn. Có $86,2 \%$ các em học sinh biết phòng tránh sâu răng bằng cách chải răng hằng ngày, ăn ít đồ ngọt chiếm tỷ lệ $61,2 \%$, súc miệng chiếm tỷ lệ $46,3 \%$ và khám răng thường xuyên là $36,6 \%$. Số hoc sinh chải răng 2 lần/ngày chiếm tỷ lệ $67,1 \%, 36,7 \%$ chải răng xoay tròn, có $54,2 \%$ học sinh 2 trường sử dụng đồ ngọt 1 đến 3 lần/ ngày.

Tư khóa: học sinh tiểu học, bệnh răng miệng, Điện Biên

\section{SUMMARY}

KNOWLEDGE AND PRACTICE ABOUT DENTAL 